\title{
AS PARCERIAS ENTRE PREFEITURAS PAULISTAS E O SETOR PRIVADO NA POLÍTICA EDUCACIONAL: EXPRESSÃO DE SIMBIOSE?*
}

\author{
THERESA ADRIÃO $0^{* *}$ \\ TEISE GARCIA ${ }^{* * *}$ \\ RAQUEL BORGHI ${ }^{* * * *}$ \\ LISETE ARELARO ${ }^{* * * * *}$
}

RESUMO: O artigo apresenta resultados finais de pesquisa interinstitucional que teve por objetivo analisar a natureza e as consequências de parcerias firmadas entre setores privados e governos municipais paulistas para atendimento da educação infantil e do ensino fundamental. O período correspondeu aos anos de 1996 a 2006, tendo em vista a percepção de que o aumento das responsabilidades dos municípios pela oferta educacional, decorrente da municipalização do ensino fundamental, poderia estimular processos de privatização da educação municipal, por meio do aumento de "parcerias" entre a gestão municipal e o setor privado lucrativo e não lucrativo. O estudo apresenta tendências relacionadas a três modalidades de parcerias: subvenção pública para oferta de vagas em instituições privadas de educação infantil, aquisição de "sistemas" privados de ensino e contratação de assessoria privada para a gestão da educação municipal. As tendências percebidas na análise indicam que as atuais relações entre as esferas públicas e privadas no campo da educação, decorrentes da descentralização havida no setor, representam um movimento em direção a sua privatização.

Palavras-chave: Privatização. Parcerias. Sistemas privados apostilados. Subvenção. Assessoria para gestão.

Trabalho aceito como excedente na 33를 Reunião Anual da ANPEd, em 2010.

* Doutora em Educação e professora da Faculdade de Educação da Universidade Estadual de Campinas (Unicamp). E-mail: theadriao@gmail.com

*** Doutora em Educação e professora da Faculdade de Filosofia, Ciências e Letras da Universidade de São Paulo (USP - Ribeirão Preto). E-mail: teise@ffclrp.usp.br

**** Doutora em Educação e professora do Departamento de Educação da Universidade Estadual Paulista "Julio de Mesquita Filho" (Unesp - Rio Claro). E-mail: raborghi@gmail.com

***** Doutora em Educação e professora da Faculdade de Educação da Universidade de São Paulo (USP). E-mail: liselaro@usp.br 


\section{PARTNERShips BeTWEen LOCAL GOVERNMENTS AND THE PRIVATE}

\section{SECTOR ON EDUCATIONAL POLICY: EXPRESSION OF SYMBIOSIS?}

ABSTRACT: The paper presents final results of an interinstitutional research that aimed analyses the nature and the consequences of partnerships between private sectors and local governments in the State of São Paulo to face childhood and fundamental education demands. The studied period was 1996 to 2006, due the perception that the municipalization process could stimulate the outsourcing and privatization of local education. The study presents the ways of partnership: public subvention to offer places in private institutions of childhood education, buy private educational "systems" and private consultancy to education local administration. The tendencies that emerge from the analysis show that the current relationships between the public and private sectors represent a movement towards the privatization.

Key words: Privatization. Partnerships. Course pack systems. Subvention. Consultancy to administration.

\section{Partenariats entre les gouvernements locaux et le Secteur} PRIVÉ SUR LA POLITIQUE DE L'EDUCATION: EXPRESSION DE SYMBIOSE?

RÉSUMÉ: L'article présente les résultats finaux de l'enquête inter-institutionnelle qui a eu pour objet d'analyser la nature et les conséquences de partenariats conclus entre des secteurs privés et des gouvernements municipaux de la métropole de São Paulo pour le service de l'éducation à la maternelle et à l'enseignement élémentaire. La période a correspondu aux années 1996 à 2006, sachant que la perception d'une augmentation des responsabilités des municipalités pour l'offre éducationnelle, suite à la municipalisation de l'enseignement élémentaire, pourrait stimuler la sous-traitance de l'offre et la privatisation de l'éducation municipale. L'étude présente des tendances en relation avec trois modalités de partenariat: subvention publique pour l'offre de places en institutions privées de l'éducation élémentaire; acquisition de "systèmes" privés de l'enseignement et recours à des cabinets de conseil privés pour la gestion de l'éducation municipale. Les tendances perçues dans l'analyse indiquent que les actuelles relations entre les sphères publiques et privées dans le champ de l'éducation, suite à la décentralisation survenue dans le secteur, représentent un mouvement dans le sens de sa privatisation.

Mots-clés: Privatisation. Partenariats. Systèmes "apostilados" (matériel didactique élaboré par l'école). Subvention. Conseil pour la gestion.

\section{Introdução}

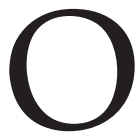

artigo apresenta resultados finais de pesquisa interinstitucional ${ }^{1}$ que teve por objetivo analisar a natureza e as consequências de parcerias firmadas entre os setores privado e governos municipais paulistas para atendimento da educação infantil e do ensino fundamental. O período selecionado para o estudo correspondeu aos anos de 1996 a 2006, tendo em vista o processo de municipalização 
do ensino fundamental induzido pelo governo estadual a partir de 1996 e reforçado pela criação do Fundo de Manutenção e Desenvolvimento do Ensino Fundamental e Valorização do Magistério (Fundef). Admitiu-se, como hipótese, que esse processo poderia estimular ações de terceirização da oferta e da privatização da educação municipal.

Nesta pesquisa, as atuais parcerias entre as esferas pública e privada representam uma tendência à privatização "entendida em sentido amplo, de modo a abranger todos os institutos de que o Estado vem lançando mão para diminuir sua estrutura e aparelhamento administrativo, o seu quadro de pessoal, o regime jurídico administrativo a que se sujeita" (Di Pietro, 2008). ${ }^{2}$ Entre esses institutos encontram-se os mecanismos viabilizadores das parcerias entre a gestão pública e o setor privado.

A pesquisa envolveu duas etapas distintas. Na primeira, foi realizado um mapeamento das parcerias público-privadas que envolvessem a educação infantil e o ensino fundamental, por meio de consultas a representantes das 645 administrações municipais do estado de São Paulo. Para efeito de caracterização, em tais consultas buscou-se identificar a natureza das parcerias, o tipo de instituição privada implicada e a modalidade.

Foram identificadas parcerias entre as esferas públicas e privadas de duas naturezas: as que incidem diretamente sobre a situação de ensino, entendidas como de natureza direta, e aquelas que incidem sobre a gestão das redes ou sistemas de ensino, com impacto indireto sobre a organização do trabalho e das práticas pedagógicas na escola, que foram consideradas como indiretas.

O tipo de instituição privada também foi critério para análise dos dados coletados. Importou saber se as parcerias envolviam instituições privadas com fins lucrativos e/ou sem fins lucrativos.

As parcerias mais frequentes foram agrupadas e categorizadas em três modalidades: subvenção pública a vagas em estabelecimentos privados, assessoria privada para a gestão educacional e compra de "sistemas" de ensino. ${ }^{3}$

Os dados levantados para o conjunto dos municípios que confirmaram possuir ou ter firmado parceria no período selecionado referem-se ainda a: ano de início e término da parceria; partido político do prefeito em exercício quando iniciada a parceria; tamanho do município em termos populacionais; matrículas na educação infantil e ensino fundamental sob responsabilidade municipal; ano de início da municipalização do ensino fundamental e ano em que o município atingiu pelo menos $40 \%$ do atendimento nesta etapa de escolaridade.

O termo "parceria" é adotado aqui como em Bezerra (2008, p. 62-63): 
A expressão parceria púbico-privada (...) implica também a capacidade de intervenção que o setor privado passa a dispor junto à administração pública, por meio da assunção total ou parcial de responsabilidades até então atribuídas ao poder público em sua totalidade.

Com frequência, as consultas aos representantes governamentais envolveram uma explicação acerca do sentido que o termo "parceria" adquiria no âmbito deste trabalho. Sobretudo no caso de parcerias para atendimento na educação infantil, estabelecidas por meio de convênios diversos, as informações eram imprecisas, o que demandou o retorno aos depoentes para checagem das informações.

Considerando os objetivos gerais da pesquisa, a segunda etapa constituiu-se de 19 estudos de caso realizados em municípios com parcerias nas modalidades destacadas, conforme o Quadro 1:

\section{Quadro 1}

Relação de estudos de caso, segundo modalidades de parcerias e porte populacional

\begin{tabular}{|c|c|c|c|}
\hline $\begin{array}{c}\text { Porte } \\
\text { populacional/ } \\
\text { modalidade de } \\
\text { parceria }\end{array}$ & $\begin{array}{l}\text { Compra de } \\
\text { “sistemas" de } \\
\text { ensino }\end{array}$ & $\begin{array}{l}\text { Subvenção pública } \\
\text { a vagas em } \\
\text { estabelecimentos } \\
\text { privados }\end{array}$ & $\begin{array}{c}\text { Assessoria } \\
\text { privada para a } \\
\text { gestão } \\
\text { educacional }\end{array}$ \\
\hline Até 10.000 hab. & Ipeúna & Altinópolis & Cosmorama \\
\hline $\begin{array}{c}10.0001 \text { a } 50.000 \\
\text { hab. }\end{array}$ & $\begin{array}{c}\text { Brotas } \\
\text { Santa Rosa de } \\
\text { Viterbo } \\
\text { Santa Gertrudes } \\
\text { Jardinópolis }\end{array}$ & Itirapina & Guariba \\
\hline $\begin{array}{c}50.001 \text { a } 100.000 \\
\text { hab. }\end{array}$ & Votuporanga & Pirassununga & Limeira \\
\hline $\begin{array}{c}100.001 \text { a } 500.000 \\
\text { hab. }\end{array}$ & Taubaté & $\begin{array}{c}\text { Hortolândia } \\
\text { Piracicaba }\end{array}$ & $\begin{array}{c}\text { São José do Rio } \\
\text { Preto }\end{array}$ \\
\hline $\begin{array}{c}\text { Mais de } 500.000 \\
\text { hab. }\end{array}$ & $\begin{array}{c}\text { São Bernardo do } \\
\text { Campo }\end{array}$ & Ribeirão Preto & $\begin{array}{c}\text { São José dos } \\
\text { Campos }\end{array}$ \\
\hline
\end{tabular}

Fonte: Adrião et al. (2009a). Os municípios de Praia Grande e São Paulo foram pesquisados, mas pela falta de informações não se constituíram em estudos de caso.

A investigação nos municípios considerou, além da análise de documentos oficiais relacionados ao objeto de investigação, a realização de entrevistas semiestruturadas (Stake, 1983) com secretários municipais em exercício nos anos de 2007 e 2008 e com técnicos das secretarias e departamentos de Educação diretamente envolvidos com a implantação das parcerias analisadas. 
As tendências decorrentes da análise do mapeamento geral constituem o objeto deste artigo, as quais indicam que as atuais relações entre as esferas públicas e privadas no campo da educação representam um movimento em direção a sua privatização. De maneira subsidiária, recorreu-se aos relatos de gestores municipais, obtidos em situação de entrevista, para maior clareza das informações, especialmente em situações de dados contraditórios.

\section{Caracterização das parcerias segundo modalidade, tipo e natureza}

Como informado anteriormente, a partir do mapeamento realizado nos municípios paulistas, três foram as modalidades de parcerias encontradas com maior frequência: a subvenção pública vagas em instituições privadas de educação infantil; a assessoria privada para a gestão educacional; a compra de "sistemas" de ensino.

A subvenção pública a vagas em estabelecimentos privados refere-se neste trabalho à modalidade em que municípios, por meio de convênios de distintos formatos, repassam recursos para instituições privadas de educação infantil. Os repassem se dão tanto para instituições privadas sem fins lucrativos, como para instituições privadas com fins lucrativos. Os primeiros já são tradicionais nesta etapa da escolaridade e os segundos constituem tendência mais atual, verificada neste estudo.

Assessoria privada para gestão educacional é entendida como a modalidade pela qual a administração pública firma convênios ou contratos com instituições privadas, tendo por objetivo: a elaboração de orientações gerais para o funcionamento da rede escolar (Plano Municipal de Educação; estatuto do magistério; alternativas de planejamento e avaliação das escolas, entre outras); a formação de gestores das escolas e de técnicos da administração municipal; a definição de estratégias e diretrizes educacionais. Assim como no caso da parceria para aquisição de vagas, as instituições parceiras do poder público podem ser privadas com e sem fins lucrativos.

Aquisição de "sistema" privado de ensino refere-se a uma forma de parceria na qual o poder público adquire os chamados "sistemas de ensino". Estes se constituem de simples somatória de produtos e serviços elaborados por instituições privadas de ensino que disputam o mercado educacional. Constatou-se, inclusive, a criação de órgãos específicos - alguns com tamanho e complexidade semelhantes ao de uma Secretaria de Educação - com o objetivo de vender às prefeituras municipais uma variedade de produtos, de maneira a atender todas as etapas de escolaridade que estejam sob a responsabilidade do município-cliente. Parte desta reflexão foi tratada neste periódico (Adrião et al., 2009a).

Ainda que a expressão "sistema de ensino", quando atribuída a este fenômeno, careça de melhor denominação, opta-se neste trabalho pela sua adoção, tendo 
em vista o seu uso corrente entre os segmentos que integram esta opção de política educacional.

Compõe a "cesta de serviços e produtos" oferecida aos municípios-clientes material didático conhecido como "material apostilado", distribuído aos estudantes e aos professores em versões distintas. Além disso, as empresas oferecem assessorias que envolvem procedimentos de avaliação sobre o uso adequado dos materiais, "treinamentos" a docentes e acesso a portais com instruções detalhadas sobre sua utilização. A empresa privada oferece ao setor público, na verdade, um programa de ensino que incide sobre a organização dos tempos e rotinas de trabalho nas unidades escolares, que constituem formas de controle sobre este trabalho. Segundo Adrião et al. (op. cit., p. 801), a parceria, portanto:

(...) representa mais do que a simples aquisição de materiais didáticos, dado se tratar de estratégia por meio da qual o setor privado amplia seu mercado, ao incidir sobre o espaço público na mesma medida em que o setor público transfere parcela de suas responsabilidades para com a educação à iniciativa privada.

A Tabela 1, na página seguinte, apresenta a distribuição anual das parcerias firmadas pelo conjunto dos 645 municípios paulistas, a partir do declarado pelos representantes do governo municipal contatados durante a pesquisa. As informações referem-se aos municípios que adotaram convênios e ou contratos ${ }^{4}$ com vista à adoção de uma das três modalidades de parceria aqui analisadas.

Pela Tabela 1 é possível constatar que no período houve pouca variação, ano a ano, no número de municípios que firmaram novas parcerias nas modalidades subvenção pública para aquisição de vagas em estabelecimentos privados e assessoria privada para gestão educacional, não obstante o elevado número de municípios em que ocorrem, entre 1996 e 2006: 61 e 33, respectivamente. No entanto, o mesmo não ocorre em relação à adoção de sistema privado de ensino. Neste caso, há um aumento crescente e significativo a partir de 2000, atingindo seu ápice no ano de 2005: são 144 parcerias firmadas no período correspondente ao estudo (1996-2006), indicando ser este um "fenômeno" mais recente e em expansão.

No caso da modalidade subvenção pública á oferta de vagas na educação infantil, do total dos 645 municípios paulistas, 61 afirmaram possuir este tipo de parceria/convênio no período. Em 15 destes municípios, os depoentes não souberam precisar o ano de início da parceria, ainda que a mesma tenha ocorrido durante a década analisada. Considerando que a identificação do ano de início da parceria é importante para as análises aqui empreendidas, nos restringiremos aos 46 municípios em que há essa definição.

Também é considerável a frequência com que os municípios paulistas firmaram parcerias para contratar assessoria privada para gestão educacional, mesmo que 
em menor grau, se comparado às modalidades anteriormente tratadas. Tomando-se em consideração a ausência de informações sobre o recurso no período anterior ao estudado, infere-se que a ampliação deste tipo de parceria compõe o movimento de simbiose entre o público e privado observado a partir da década de 1990, mais precisamente, a partir do aumento de responsabilidades educacionais por parte dos municípios paulistas. Afinal, consideradas as três modalidades de parcerias estudadas no período de 1996-2006, foram firmadas, no total, 238 parcerias, que representam número significativo dessas iniciativas.

\section{Tabela 1}

Total de parcerias implantadas no período de 1996 a 2006, segundo declaração de representantes das prefeituras

\begin{tabular}{|c|c|c|c|}
\hline $\begin{array}{l}\text { Ano e início da } \\
\text { parceria }\end{array}$ & $\begin{array}{c}\text { Sistemas privados } \\
\text { de Ensino }\end{array}$ & $\begin{array}{c}\text { Subvenção } \\
\text { pública a vagas em } \\
\text { estabelecimentos } \\
\text { privados* }\end{array}$ & $\begin{array}{l}\text { Assessoria na } \\
\text { gestão }\end{array}$ \\
\hline 1996 & 0 & 2 & 0 \\
\hline 1997 & 0 & 4 & 4 \\
\hline 1998 & 1 & 3 & 1 \\
\hline 1999 & 2 & 7 & 2 \\
\hline 2000 & 7 & 2 & 0 \\
\hline 2001 & 11 & 4 & 2 \\
\hline 2002 & 14 & 5 & 3 \\
\hline 2003 & 16 & 7 & 4 \\
\hline 2004 & 14 & 2 & 6 \\
\hline 2005 & 48 & 6 & 8 \\
\hline 2006 & 31 & 4 & 3 \\
\hline $\begin{array}{c}\text { Ano não } \\
\text { informado/ } \\
\text { entre 1996-2006 }\end{array}$ & 0 & 15 & 3 \\
\hline TOTAL & 144 & 61 & 33 \\
\hline
\end{tabular}

Fonte: Adrião et al. (2009a).

*35 municípios declararam ter parcerias com entidades privadas para a oferta da educação infantil iniciada antes de 1996 , o que corresponde a 5,42\% do total dos municípios paulistas. 


\section{Relações entre parcerias, porte populacional e municipalização do ensino fundamental no estado de São Paulo}

Merece destaque a relação entre a municipalização do ensino fundamental e a adoção das parcerias no período de 1996-2006. Os dados indicam que, entre aqueles que adotaram parceria para a assessoria na gestão educacional, a maioria tem porte populacional de até 50 mil habitantes. Todos os 33 municípios assumiram mais de $40 \%$ das matrículas do ensino fundamental. Vale lembrar ainda que a distribuição das modalidades de parceria pelo conjunto dos municípios não é equânime e parece variar em função do tamanho do mesmo e, por conseguinte, das demandas que lhes são mais evidentes, conforme indica a Tabela 2:

\section{Tabela 2}

Relação entre porte populacional e modalidades de parcerias (1996-2006)

\begin{tabular}{|l|c|c|c|c|}
\hline Porte populacional & $\begin{array}{c}\text { Número total } \\
\text { de municípios } \\
\text { por parte } \\
\text { populacional }\end{array}$ & $\begin{array}{c}\text { Sistemas } \\
\text { privados de } \\
\text { ensino }\end{array}$ & $\begin{array}{c}\text { Subvenção pública } \\
\text { a aquisiça de vagas } \\
\text { em estabelecimentos } \\
\text { privados }\end{array}$ & $\begin{array}{c}\text { Assessoria } \\
\text { privada para } \\
\text { a gestão } \\
\text { educacional }\end{array}$ \\
\hline Até 10.000 hab. & 278 & 66 & 2 & 3 \\
\hline 10.0001 a 50.000 hab. & 245 & 68 & 17 & 20 \\
\hline 50.001 a 100.000 hab. & 49 & 6 & 11 & 8 \\
\hline 100.001 a 500.000 hab. & 63 & 4 & 14 & 2 \\
\hline Mais de 500.000 hab. & 10 & 0 & 2 & 33 \\
\hline Total & 645 & 144 & 46 & 0 \\
\hline
\end{tabular}

Fonte: Adrião et al. (2009a).

Se focarmos a atenção no número de habitantes dos municípios pesquisados, tendo em vista o censo populacional de 2000, conforme Tabela 2, verificamos que a aquisição de "sistemas" privados de ensino, no período considerado é quase exclusiva aos municípios com até 50 mil habitantes. A contratação de assessorias privadas para a gestão da educação tem uma distribuição mais regular, ainda que concentrada em dois grupos: municípios com até 50 mil habitantes e com população entre 100.001 
e 500 mil habitantes. Já a modalidade subvenção pública a vagas em estabelecimentos privados esteve presente em todos os municípios de diferentes portes populacionais. Observou-se que, nos municípios a partir de 50 mil habitantes, a subvenção na oferta de vagas ocorreu com maior frequência do que nos municípios menores.

O mapeamento permitiu, ainda, analisar as relações existentes entre o processo de municipalização do ensino fundamental em São Paulo e a evolução das parcerias no período, tendo em vista duas informações: o ano em que iniciaram a municipalização do ensino fundamental e o ano em que passaram a responder por, no mínimo, $40 \%$ do atendimento a esta etapa de escolaridade, porcentual que se aproxima do que, no entendimento dos gestores entrevistados, correspondeu a uma alteração de qualidade no desenho e demanda da educação ofertada pelo município.

Percebe-se que há dois momentos de evidente alteração no desenho da oferta do ensino fundamental (EF) pelo conjunto de municípios com subvenção pública para a oferta de vagas: um que compreende os anos de 1996 e 1997, nos quais se acentua a municipalização desta etapa de escolaridade no estado de São Paulo, e outro que compreende os anos de 1997 a 2001, nos quais se verifica a concentração de maior número de municípios que assumiram no mínimo 40\% das matrículas do EF.

$\mathrm{O}$ movimento relativo à assunção das matrículas no EF, percebido pelo conjunto dos 33 municípios que declararam ter estabelecido parceria para assessoria na gestão educacional, fundamenta a afirmação anterior: concentração da municipalização nos anos iniciais do período analisado (1996 e 1997) e aumento deste atendimento para no mínimo 40\%, principalmente entre 1997 e 1999 e, depois, 2002. Apenas três municípios não optaram pela municipalização dentro deste período.

No caso das parcerias para adoção de sistemas privados, o movimento se repete: concentração da municipalização nos anos iniciais do período e ampliação do atendimento pelo município, especialmente em 1997, 1999 e 2002.

Em síntese, as concentrações indicadas correspondem a dois momentos do processo de municipalização da etapa do EF no Estado. O primeiro, que antecede ao Fundef, decorreu de forte indução do governo estadual em 1995 à assunção do EF pelos municípios, de sorte que concentra um aumento na quantidade de municípios que assumiram esta etapa de escolaridade. Já o segundo momento representa a ação do Fundef e do governo do PSDB sobre os munícipios na direção do aprofundamento do processo de municipalização, por meio da ampliação do atendimento ao EF.

Comparando-se tal indicação ao Gráfico 1, que ilustra a relação anual de parcerias firmadas pelos municípios, pode-se observar que o aumento no número de parcerias firmadas para a subvenção pública a vagas privadas é maior em dois momentos: 1997, ano em que um maior número de municípios inicia a municipalização, 
e 1999, quando se eleva o número de municípios responsáveis pela oferta igual ou superior a $40 \%$ do EF, podendo-se afirmar que os mesmos se encontravam convencidos de que ao aumento de suas responsabilidades corresponderia um aumento proporcional na transferência de recursos financeiros aos seus municípios.

Nos casos dos municípios que contrataram assessorias para gestão e para aquisição de sistemas privados, ainda que haja uma pequena elevação no começo do período, observamos uma tendência de aumento a partir de 2000 com uma elevação acentuada em 2005. Também em ambos os casos, em 2004, último ano das gestões municipais, registra-se uma ligeira queda.

\section{Gráfico 1}

Parcerias firmadas entre 1996 e 2006

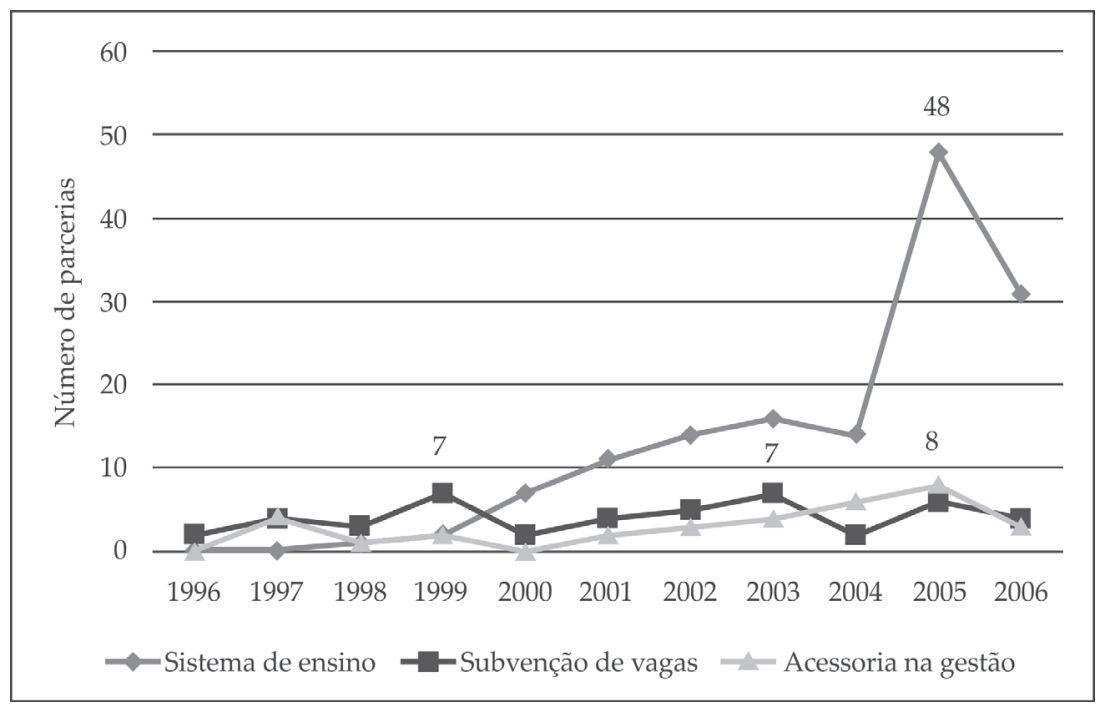

Fonte: Adrião et al. (2009a).

Os dados da pesquisa permitiram constatar que a municipalização do ensino fundamental levou a um aumento da subvenção pública às instituições privadas que atendem à educação infantil, e a esta relação agrega-se outra variável importante quando se trata das modalidades aquisição de sistemas privados e assessoria para gestão. Os depoimentos dos gestores entrevistados e os anos em que se concentram a elevação no número de parcerias nestes casos indicaram também uma relação imediata entre tais medidas e o início de novas gestões nos municípios: 2001 e 2005. Para os entrevistados, a presença destas parcerias poderia significar "diferencial" no campo da educação e representaria um marco dos novos governos. 
Em função da modalidade da parceria, constatamos diferenciações nos tipos de instituições privadas contratadas. Temos assim, no caso da subvenção para oferta de vaga, a prevalência de instituições de natureza filantrópica, ou seja, sem fins lucrativos. Todavia, observamos um movimento nessa modalidade de parceria em direção à subvenção de vagas por parte do poder público em instituições privadas stricto sensu, isto é, com fins lucrativos, conforme atestam dois dos casos estudados. Dos municípios com parcerias para a oferta de vagas na educação infantil, nove subvencionavam instituições privadas lucrativas, durante o período estudado (1996-2006). Nos demais municípios, os convênios foram realizados com instituições privadas sem fins lucrativos.

Em relação às assessorias privadas para a gestão educacional, localizamos a presença das instituições do terceiro setor, representadas por organizações não governamentais, como institutos e fundações. Os casos estudados nesta modalidade encontravam-se todos com parcerias junto a instituições sem fins lucrativos, conforme pode ser verificado no Quadro 2, na página seguinte.

As parcerias analisadas redundaram em alterações na gestão das secretarias municipais de Educação e nas unidades de ensino. Aquelas de menor duração, como no caso das efetuadas com o Instituto Protagonistés, constituíram-se por cursos destinados aos gestores escolares. Já o Instituto Ayrton Senna implantou programas que interferiram na gestão da Secretaria Municipal de Educação, com incidência direta sobre a organização do trabalho escolar, por meio da definição de diretrizes e metas relacionadas ao desempenho de alunos, escolas e profissionais. Intervenções assemelhadas ocorreram com a parceria entre o Instituto Embraer, a Fundação Pitágoras e os municípios envolvidos e com a atuação da Fundação Limeira.

Embora as parcerias estudadas apresentassem características específicas, em comum as instituições privadas mantinham: princípios orientadores para a ação originados na administração empresarial, declaradamente ou não; ênfase no papel das lideranças para a melhoria do desempenho escolar; introdução de procedimentos centralizados e uniformes de avaliação e formas de premiação ou reconhecimento público pelo sucesso alcançado.

No caso da modalidade aquisição de sistema privado de ensino, as empresas parceiras dos municípios eram todas empresas privadas com fins lucrativos. Entre estas, três grandes grupos empresariais - o Colégio Oswaldo Cruz (COC), o Grupo Objetivo e o Grupo Positivo - possuíam considerável inserção na educação pública paulista. Como já dissemos em outra oportunidade (Adrião, 2008; Adrião et al., 2009a, 2009b), há maior concentração deste tipo de contrato nos municípios com até 50 mil habitantes, os quais totalizam cerca de $80 \%$ dos municípios paulistanos. Outra informação relevante é o evidente aumento desta modalidade no ano de 2005. 


\section{Quadro 2}

Relação de estudos de caso na modalidade assessorias privadas para gestão educacional, segundo o porte populacional, município, instituição privada, programa desenvolvido e anos informados de início e término das parcerias

\begin{tabular}{|c|c|c|c|c|c|}
\hline $\begin{array}{c}\text { Porte } \\
\text { populacional }\end{array}$ & Município & Instituição privada & Programa & $\begin{array}{l}\text { Ano de início } \\
\text { da parceria }\end{array}$ & $\begin{array}{c}\text { Ano de } \\
\text { término da } \\
\text { parceria }\end{array}$ \\
\hline $\begin{array}{c}\text { Até } \\
10.000 \text { hab. }\end{array}$ & Cosmorama & $\begin{array}{l}\text { Protagonistés } \\
\text { Instituto de } \\
\text { Protagonismo } \\
\text { Jovem e Educação }\end{array}$ & $\begin{array}{l}\text { Curso Gestão } \\
\text { para o Sucesso } \\
\text { Escolar }\end{array}$ & 2003 & 2004 \\
\hline $\begin{array}{c}10.0001 \mathrm{a} \\
50.000 \mathrm{hab} .\end{array}$ & Guariba & $\begin{array}{l}\text { Protagonistés } \\
\text { Instituto de } \\
\text { Protagonismo } \\
\text { Jovem e Educação }\end{array}$ & $\begin{array}{l}\text { Curso Gestão } \\
\text { para o Sucesso } \\
\text { Escolar }\end{array}$ & 2003 & 2004 \\
\hline \multirow{2}{*}{$\begin{array}{c}50.001 \mathrm{a} \\
100.000 \text { hab. }\end{array}$} & $\begin{array}{l}\text { Praia } \\
\text { Grande }\end{array}$ & $\begin{array}{l}\text { Protagonistés } \\
\text { Instituto de } \\
\text { Protagonismo } \\
\text { Jovem e Educação }\end{array}$ & $\begin{array}{l}\text { Curso Gestão } \\
\text { para o Sucesso } \\
\text { Escolar }\end{array}$ & 2003 & 2004 \\
\hline & Limeira & Fundação Limeira & $\begin{array}{c}\text { Programa } \\
\text { Gestão de } \\
\text { Qualidade Total } \\
\text { em Educação }\end{array}$ & 1997 & $\begin{array}{l}\text { Em vigor } \\
\text { até } 2006\end{array}$ \\
\hline $\begin{array}{c}100.001 \mathrm{a} \\
500.000 \mathrm{hab} .\end{array}$ & $\begin{array}{l}\text { São José do } \\
\text { Rio Preto }\end{array}$ & $\begin{array}{c}\text { Instituto Ayrton } \\
\text { Senna }\end{array}$ & $\begin{array}{c}\text { Programa } \\
\text { Gestão Nota } 10\end{array}$ & 2001 & $\begin{array}{l}\text { Em vigor } \\
\text { até } 2006\end{array}$ \\
\hline $\begin{array}{c}\text { Mais de } \\
500.000 \text { hab. }\end{array}$ & $\begin{array}{c}\text { São José } \\
\text { dos } \\
\text { Campos }\end{array}$ & Instituto Embraer & $\begin{array}{c}\text { Sistema } \\
\text { de Gestão } \\
\text { Integrado }\end{array}$ & 2002 & 2004 \\
\hline
\end{tabular}

Fonte: Adrião et al. (2009a).

\section{Considerações finais}

Ao retomarmos o referencial teórico que orienta a reflexão sobre as parcerias entre os setores público e privado na esfera educacional, temos a considerar, inicialmente, que o incentivo às parcerias encontra estímulo nas orientações governamentais para a gestão pública no Brasil desde o Plano Diretor para a Reforma da Administração e Aparelho do Estado (1995), a partir do qual se configurou um conjunto legal que, ao mesmo tempo em que ampliou o controle sobre a atuação das administrações públicas, com destaque para as de nível local, estimulou essas mesmas esferas governamentais a buscarem na iniciativa privada apoio logístico 
e operacional para as responsabilidades assumidas, especialmente se relativas às políticas sociais.

Não é de se menosprezar o papel indutor à privatização, a qual inclui todos os mecanismos de terceirização, desempenhados, em especial, pela Emenda Constitucional (EC) n. 19/1998 e pela chamada Lei de Responsabilidade Fiscal (Lei Complementar n. 101/2000).

Na área educacional, desde a EC n. 14/1996 e a Lei de Diretrizes e Bases da Educação Nacional (LDB) (Lei n. 9.394/96), o setor privado é compreendido como portador das competências necessárias à qualificação dos serviços públicos e o Estado, a partir das mudanças de competências da União introduzidas por aquela EC e pela LDB, como responsável pela adequada coordenação dos mesmos. Não por acaso, naquele momento histórico a proposta de criação de um Sistema Nacional de Educação foi substituída por uma propondo um Sistema Nacional de Avaliação, hoje plenamente implantado.

Das provas nacionais e estaduais, crescentes numericamente a cada ano - tais como o Sistema de Avaliação da Educação Básica (Saeb), a Prova Brasil e a Provinha Brasil, em nível nacional, e o Sistema de Avaliação de Rendimento Escolar do Estado de São Paulo (Saresp), em nível estadual -, e das propostas de indicadores de competência dos sistemas educacionais - o Ideb, nacionalmente, e o Idesp, no estado de São Paulo -, pode-se depreender o estímulo aos ranqueamentos entre cidades e entre escolas e à adoção de medidas de "sucesso escolar" bastante assemelhadas aos processos desenvolvidos pelas empresas, em suas análises de desempenho gerencial e de propostas de competitividades comercial.

Do cenário político nacional para as proposições no âmbito do estado de São Paulo, verifica-se também, como fator a estimular as parcerias, o processo de municipalização do ensino fundamental e a implantação do Fundef, que levou a uma ampliação das responsabilidades municipais em um cenário, muitas vezes, de precariedade técnica, administrativa e financeira. Percepção esta já indicada por Barreto (1995) e analisada por Arelaro (1999).

As parcerias entre os setores público e privado, firmadas por prefeituras no período da pesquisa (1996/2006), ocorreram em municípios dirigidos por 14 diferentes partidos políticos, sendo que cerca de $5 \%$ dos contatados não informaram o partido em exercício, quando do início da parceria. Entretanto, observou-se que tal procedimento foi encontrado nas administrações do PSDB $(27,86 \%)$, do PMDB (14,75\%), do PFL (7,10\%) e do PT (5,46\%). Destaca-se a adoção em maior escala pelo PSDB.

Observou-se ainda que, no caso da contratação de assessorias para gestão educacional, prevaleceu a presença de instituições privadas integrantes do chamado "terceiro setor". Ainda que não haja consenso a respeito do que venham a ser tais 
instituições, é sabido que a generalização de organizações da sociedade civil (ONGs, fundações, institutos) tem sido induzida por orientações políticas alicerçadas na chamada "terceira via" (Giddens, 2000). Na América Latina, tais orientações voltaram-se para reforçar a atuação do Estado como formulador e financiador de políticas públicas, para o que seria fundamental desenvolver a capacidade para "atrair a comunidade, as empresas ou o Terceiro Setor para compartilhar a responsabilidade pela execução dos serviços públicos, principalmente os de saúde e educação básica" (Clad, 1998, p. 4).

Finalmente, a pesquisa indicou que a esfera pública, e mais precisamente as diferentes etapas e modalidades da educação básica, tem se constituído como um espaço adicional para a reprodução e ampliação do capital, o qual encontrava limites no crescimento de estabelecimentos privados de ensino, como atestam os estagnados dados de matrícula na rede privada nos censos educacionais (MEC/Inep - Sinopses Estatísticas), mantidos em 10\% do total das matrículas da educação básica, nos últimos 30 anos.

As empresas privadas lucrativas não oferecem apenas materiais didáticos ou formação docente, mas atuam também sobre a política educacional no que diz respeito à organização do ensino local. O poder público, por sua vez, delega parcela de suas responsabilidades específicas para com a educação, muitas vezes recém assumidas, para a iniciativa privada, por se sentir "incompetente" para atingir as metas oficiais nacionais ou internacionais - da OCDE, do Ideb, do Idesp ou do teste Pisa - que estes próprios setores propuseram ou estimularam.

No caso da subvenção pública a vagas ofertadas por estabelecimentos privados, a maior incidência em municípios de elevado porte populacional pode ser associada a razões como: presença de grupos organizados, com significativa capacidade de pressão, presença mais efetiva do Ministério Público ou, ainda, existência de maior demanda.

Em síntese, o estudo demonstrou que a descentralização da educação básica fez-se acompanhar, no estado de São Paulo, por mecanismos de transferência de funções da esfera governamental para a esfera privada, inaugurando o que alguns autores identificam como uma nova forma de regulação da educação básica (Barroso, 2005). Neste caso, com uma supremacia de interesses privados, cujas consequências para a democratização da educação como direito ainda estão por ser percebidas.

Pode-se afirmar que tais processos de transferência inauguram, na esfera dos governos subnacionais, arranjos político-administrativos que implicam alterações nas lógicas decisórias ao incorporarem setores sociais até recentemente inexistentes nessa esfera governamental: os chamados "novos filantropos" (Robertson et al., 2012) e o setor empresarial privado, vinculado ou não ao capital internacional. 
No Brasil, mais especificamente em São Paulo, essa presença, ao condicionar as opções de políticas educacionais, tal como apresentado neste artigo, caracteriza o que denominamos de simbiose entre as esferas pública e privada. O termo, emprestado das ciências biológicas, objetiva destacar as tendências de alterações decorrentes de mecanismos adaptativos observados no interior do setor privado, principalmente no campo da educação pública, tendo em vista a subordinação da política educacional aos serviços e produtos oferecidos pelos parceiros privados, atendendo aos seus interesses comerciais.

\section{Notas}

1. Pesquisa financiada pela Fundação de Amparo à Pesquisa do Estado de São Paulo (Fapesp).

2. Acesso em 2 de dezembro de 2008.

3. Esta última modalidade recebeu tratamento em artigo publicado neste periódico, no ano de 2009 (Adrião et al., 2009b).

4. O Decreto Federal n. 93.872/1986 define e diferencia contrato e convênio: “Os serviços de interesse recíproco dos órgãos e entidades de administração federal e de outras entidades públicas ou organizações particulares poderão ser executados sob regime de mútua cooperação, mediante convênio, acordo ou ajuste. Quando os participantes tenham interesses diversos e opostos, isto é, quando se desejar, de um lado, o objeto do acordo ou ajuste, e de outro lado a contraprestação correspondente, ou seja, o preço, o acordo ou ajuste constitui contrato." (art. 48, § 1ํㅡ, grifos nossos).

\section{Referências}

ADRIÃO, T. Considerações sobre a privatização da educação pública paulista: notas sobre o aumento das parcerias entre governos municipais e iniciativa privada. In: SOUZA, C.G.; RIBEIRO, P.R.M. (Org.). Política, gestão educacional e formação de educadores: contribuições ibero-americanas para a educação. Araraquara: Cultura Acadêmica; Unesp; Instituto de Estudios Latinoamericanos da Universidad de Alcala y He, 2008. v. 10, p. 32-45.

ADRIÃO, T. et al. Estratégias municipais para a oferta da educação básica: análise de parcerias público-privado no estado de São Paulo. São Paulo: Fapesp, 2009a. 360p. (Relatório de pesquisa).

ADRIÃO, T. et al. Sistemas apostilados e gestão privada da educação pública em São Paulo. Educação \& Sociedade, Campinas, v. 30, n. 108, p. 183-198, 2009 b.

ARELARO, L.R.G. A municipalização do ensino no estado de São Paulo: antecedentes históricos e tendências. In: OLIVEIRA, C. et al. Municipalização do ensino no Brasil: algumas leituras. Belo Horizonte: Autêntica, 1999. v. 1, p. 61-89.

BARRETO, E.S.S. Descentralizar e redistribuir nos sistemas de ensino. Cadernos de Pesquisa, São Paulo, n. 95, p. 73-78, 1995. 
BARRETO, E.S.S.; ARELARO, L.R.G. A municipalização do ensino de $1^{\circ}$ grau: tese controvertida. Em Aberto, Brasília, DF, v. 5, n. 29, p. 1-13, jan./mar. 1988.

BARROSO, J. O Estado, a educação e a regulação das políticas públicas. Educação \& Sociedade, Campinas, v. 26, n. 92, p. 725-751, out. 2005.

BEZERRA, E. Parceria público-privada nos municípios de Brotas e Pirassununga: estratégias para a oferta do ensino? 2008. Dissertação (Mestrado em Biociências) - Instituto de Biociências, Universidade Estadual Paulista, Rio Claro.

BRASIL. Emenda Constitucional n. 14, de 12 de setembro de 1996. Modifica os arts. 34, 208, 211 e 212 da Constituição Federal, e dá nova redação ao art. 60 do Ato das Disposições Constitucionais Transitórias. Diário Oficial da União, Brasília, DF, 13 set. 1996.

BRASIL. Lei n. 9.394, de 20 de dezembro de 1996. Estabelece as diretrizes e bases da educação nacional. Diário Oficial da União, Brasília, DF, 23 dez. 1996.

BRASIL. Lei Complementar n. 101, de 4 de maio de 2000. Estabelece normas de finanças públicas voltadas para a responsabilidade na gestão fiscal e dá outras providências. Diário Oficial da União, Brasília, DF, 5 maio 2000.

BRASIL. Presidência da República. Plano Diretor da Reforma do Aparelho do Estado. Brasília, DF: Imprensa Nacional, 1995.

CAMPOS, M.M. et al. Creches e pré-escolas no Brasil. São Paulo: Cortez, 1993.

CENTRO LATINO AMERICANO DE ADMINISTRAÇÃO PARA O DESENVOLVIMENTO (CLAD). Uma nova gestão pública para a América Latina. 1998. Disponível em: $<$ http:www.bresserwesite.org.br>. Acesso em: 15 jul. 2008.

DI PIETRO, M.S. Reflexões sobre as parcerias público-privadas. 2008. Disponível em: $<$ http://www.azevedosette.com.br/ppp/artigos/reflexoes.html> Acesso em: $20 \mathrm{dez}$. 2009.

GIDDENS, A. A terceira via: reflexões sobre o impasse político atual e o futuro da social-democracia. Rio de Janeiro: Record, 2000.

ROBERTSON, S. et al.(Ed.). Public private partnerships in education: new actors and modes of governance in a globalizing world. London: Edward Elgar, 2012.

ROCKWELL, E. Etnografia e teoria na pesquisa educacional. In: EZPELETA, J.; ROCKWELL, E. Pesquisa participante. São Paulo: Cortez, 1986. p. 31-54.

SAVIANI, D. A Nova Lei da Educação: trajetória, limites e perspectivas. Campinas: Autores Associados, 1997. 
SILVA, J.A. Comentário contextual à Constituição. São Paulo: Malheiros, 2005. p. 768.

STAKE, R.E. Pesquisa qualitativa/naturalista: problemas epistemológicos. Educação E Seleção, São Paulo, n. 7, p. 19-27, jan./jun. 1983.

Recebido em 6 de março de 2011.

Aprovado em 8 de maio de 2012. 